\title{
The Making of HOWL by Anish Kapoor: a Fitting Inflated Sculpture
}

\author{
*Artem Holstov and Adam Bown \\ * Tensys \\ 1 St. Swithins Yard, Walcot St., Bath, UK, BA1 5BG \\ E-mail: artem.holstov@tensys.com \\ Tel: +447778314377

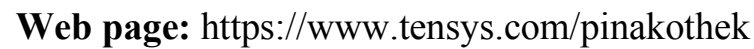

\begin{abstract}
Contemporary art is often abstract and enigmatic. In many cases, it is not meant to be understood, but rather is experienced. Contemporary artists employ symbolic, sometimes, instinctive associations to certain colours, shapes and patterns to instigate an emotional response from the viewer. To achieve this, their works can be purposefully distanced from realism and be devoid of superfluous details. However, this minimalistic approach does not always apply to the scale of the artworks. One of the most influential contemporary artists, Anish Kapoor, is famous for his monumental installations that blur the boundaries between architecture and sculpture. His latest work, entitled "HOWL", is a sitespecific inflated fabric form installed in the Rotunda of the Pinakothek der Moderne, Munich, Germany in September 2020 to mark the 18-year anniversary of the museum opening. At $21.5 \mathrm{~m}$ in diameter and $14.3 \mathrm{~m}$ in depth, the burgundy-coloured ellipsoidal form is the largest exhibit that has ever been displayed in the museum. It fills the Rotunda and is seemingly squeezed between its columns extending naturally into the spaces between them and hanging at the height of $2.75 \mathrm{~m}$ over the ground. This creates a powerful visual and formative interaction between the art object and the building, which has been a focal design intention.

The enormous pneumatic sculpture had to be tailored perfectly to the building to convey this effect. Any deviations from the desired form could lead to wrinkles, overstressed or slack fabric areas and loss of symmetry, which would impact the fine art work aesthetically and could even prevent its installation. Tensys have been tasked to realise the artist's vision of HOWL, undertaking fabric analysis and patterning. This paper presents the methods used to address the engineering challenges in this project, including parametric CAD and FEA tools for optimisation of the shape and the consideration of material behaviour and the effects of inflation pressure and contact with the columns on the form and material stresses.
\end{abstract}

